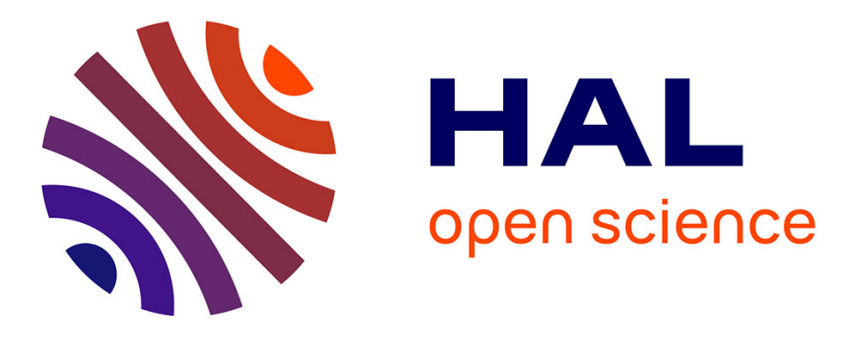

\title{
Prediction of the production kinetics of the main fermentative aromas in winemaking fermentations
}

Jean-Roch Mouret, Vincent Farines, Jean-Marie Sablayrolles, Ioan-Cristian Trelea

\section{- To cite this version:}

Jean-Roch Mouret, Vincent Farines, Jean-Marie Sablayrolles, Ioan-Cristian Trelea. Prediction of the production kinetics of the main fermentative aromas in winemaking fermentations. Biochemical Engineering Journal, 2015, 103, pp.211-218. 10.1016/j.bej.2015.07.017 . hal-01310595

\section{HAL Id: hal-01310595 \\ https://hal.science/hal-01310595}

Submitted on 5 Oct 2017

HAL is a multi-disciplinary open access archive for the deposit and dissemination of scientific research documents, whether they are published or not. The documents may come from teaching and research institutions in France or abroad, or from public or private research centers.
L'archive ouverte pluridisciplinaire HAL, est destinée au dépôt et à la diffusion de documents scientifiques de niveau recherche, publiés ou non, émanant des établissements d'enseignement et de recherche français ou étrangers, des laboratoires publics ou privés. 
Title:

Prediction of the production kinetics of the main fermentative aromas in winemaking fermentations

Mouret J.R. ${ }^{1 *}$, Farines V. ${ }^{1,2}$, Sablayrolles J.M. ${ }^{1}$, Trelea I.C. ${ }^{3}$

${ }^{1}$ INRA, UMR1083, 2 Place Viala, F-34060 Montpellier Cedex 1, France

2 Universite Montpellier, UMR1083, 2 Place Viala, F-34060 Montpellier Cedex 1, France

${ }^{3}$ AgroParisTech, INRA, UMR 782, F-78850 Thiverval-Grignon, France

${ }^{*}$ Corresponding author: Tel: +33-4-99-61-22-74; Fax: +33-4-99-61-28-57

E-mail address: mouretj@supagro.inra.fr 


\section{Abstract:}

A novel dynamic model was developed for predicting the synthesis kinetics of the principal aroma compounds produced by yeasts during winemaking fermentations: isobutanol, isoamyl alcohol, isoamyl acetate, ethyl hexanoate and ethyl octanoate. The parameters of the model were identified from nine fermentations performed at temperatures between 18 and $30^{\circ} \mathrm{C}$ and with different initial nitrogen contents, in the range of 70 to $410 \mathrm{mgN} / \mathrm{L}$. The model was validated in six independent experiments with conditions in the same range. Predictions were accurate for these volatile compounds: the mean difference between experimental and estimated values for fermentative aroma synthesis throughout the process was below $10 \%$, for both the fermentations used to build the model and those used for validation. This model is the first to simulate the production kinetics of fermentative aromas and provides new insight into the synthesis of these volatile compounds. It will facilitate the development of innovative strategies for controlling the production of those aromas in winemaking, through management of the principal control factors: assimilable nitrogen content and temperature during the alcoholic fermentation.

\section{Keywords:}

Bioprocess monitoring; dynamic modelling; fermentation; yeast; aroma compounds; wine. 


\section{Introduction}

Wine aroma is one of the principal attributes determining consumer preference [1-3]. Most fruity aroma compounds, including esters in particular, are produced by the yeast during alcoholic fermentation. Several studies have assessed the influence of fermentation parameters on the final fermentative aroma content of the wine, focusing mostly on higher alcohols and esters [2]. These final concentrations are influenced principally by the concentration of assimilable nitrogen [2]. The synthesis of higher alcohols is not a monotonic function of initial nitrogen content; production is optimal for an initial assimilable nitrogen content of 200 to $300 \mathrm{mg} / \mathrm{L}$ [4-8]. The final concentrations of both acetate and ethyl esters are generally higher for musts with high initial nitrogen contents [3,6,9-11]. Fermentation temperature is the second most important factor influencing the final aroma composition of the wine. Larger amounts of higher alcohols are generally produced at higher temperatures [12,13], but this relationship is not systematic [14] and depends of the compound studied [6]. By contrast, the final liquid concentrations of esters are systematically lower at high temperatures, particularly for ethyl esters $[6,7,12,14]$.

Despite the large number of studies carried out, the available data are highly fragmentary. There is also currently no model mimicking the production kinetics of fermentative aroma compounds during the process of fermentation. The available dynamic models focus on the main reaction of the alcoholic fermentation: the bioconversion of sugars into ethanol and $\mathrm{CO}_{2}$ [15-22]. 
In this study, we determined the production kinetics of the main fermentative aromas for various values of initial nitrogen concentration and temperature, using an online monitoring device [23]. We then used the data collected to construct the first dynamic model predicting the synthesis of five fermentative aromas (two higher alcohols, one acetate ester and two ethyl esters) during the process of fermentation.

\section{Materials and Methods}

The data used to build the model were obtained in a previous study [6], in which nine pilot-scale fermentations were performed with musts containing three levels of assimilable nitrogen $(70,230$ and $410 \mathrm{mgN} / \mathrm{L})$, at three temperatures $(18,24$ and $\left.30^{\circ} \mathrm{C}\right)$, corresponding to the conditions generally used in winemaking. The concentrations of volatile compounds in the headspace of the fermenter were monitored with a specific online GC system [23].

Only the additional experiments used for model validation are described below.

\section{$\underline{2.1 \text { Fermentation }}$}

\subsubsection{Yeast strain and culture media}

Fermentations were carried out with the commercial Saccharomyces cerevisiae strain Lalvin EC 1118® (Lallemand SA, Montreal, Canada). Fermentation tanks were inoculated with $200 \mathrm{mg} / \mathrm{L}$ active dry yeast rehydrated by incubation with $50 \mathrm{~g} / \mathrm{L}$ glucose for 30 minutes at $35^{\circ} \mathrm{C}$. 
We used different synthetic media (SMn, with ' $n$ ' indicating the assimilable nitrogen content) mimicking grape musts [24]. The concentrations of sugars, salts, vitamins, trace elements and anaerobic factors and the proportions of the various nitrogen sources were identical to those used by Mouret et al. [6]. Yeast assimilable nitrogen (YAN) concentration ranged from 150 to $340 \mathrm{mgN} / \mathrm{L}$ (SM150, SM230 and SM340).

\subsubsection{Tanks and fermentation control}

Fermentations were run at pilot scale, in 10-liter stainless steel tanks, at 21, 24 and $26^{\circ} \mathrm{C}$. The amount of $\mathrm{CO}_{2}$ released was measured automatically with a gas mass flow meter, for online measurement of the rate of $\mathrm{CO}_{2}$ production $\left(\mathrm{dCO}_{2} / \mathrm{dt}\right)$.

The reproducibility of the experiments was assessed by performing the fermentation in SM230 at $24^{\circ} \mathrm{C}$ in triplicate. For all the volatile compounds assessed, the coefficient of variation for the gas concentration between the triplicates was low throughout the process of fermentation, with mean values of $7 \%, 9 \%, 6 \%, 6 \%$ and $6 \%$ for isobutanol, isoamyl alcohol, isoamyl acetate, ethyl hexanoate and ethyl octanoate, respectively. Based on these low coefficients of variation, the other fermentation trials were each performed only once.

\subsection{Analysis of higher alcohols and esters}

\subsubsection{Online monitoring}

The concentrations of volatile compounds in the headspace of the fermenters were measured hourly, with an online GC device [23]. Five fermentative aromas from three chemical families were considered: two higher alcohols (isobutanol, isoamyl alcohol), 
one acetate ester (isoamyl acetate) and two ethyl esters (ethyl hexanoate, ethyl octanoate). The concentrations of these compounds in the liquid phase were calculated with previously determined gas/liquid partition coefficients $[25,26]$.

\subsubsection{Volatile compound balances during fermentation}

Gas-liquid balances were calculated for the five volatile compounds considered $[6,23]$. For each molecule, losses in the gas, accumulation in the liquid and total production $(\mathrm{M})$ were determined throughout the fermentation process.

Total production was calculated by adding the amount remaining in the liquid phase to the amount lost in the gas phase [25]. This total production corresponds to the total amount of the compound produced by the yeast and is therefore related to yeast metabolism.

\subsection{Modeling}

The mathematical model (presented in Section 3) was implemented in Matlab 7 (The Matworks Inc., Natick, MA). The parameters were identified by nonlinear regression analysis, with Statistic Toolbox in Matlab. Full details on the parameter identification procedure are given in section 3.1.4.

\section{Results and Discussion}

\section{$\underline{3.1 \text { Model construction }}$}


In a previous study, we highlighted specific relationships between sugar consumption and the total production of volatile compounds, depending on the fermentation conditions [6]. We showed that, for any fermentation, there are two successive linear phases of aroma compound production from sugar [6], as illustrated in Figures 1a and $1 \mathrm{~b}$. We therefore began by modeling changes in the production yields of these compounds (aroma compound vs. sugar) from the initial nitrogen concentration and temperature values. We then integrated these yields into a previously developed model predicting the kinetics of sugar consumption during the fermentation process (called MOMAF, for "modeling of the main reaction of alcoholic fermentation", [19]). We thus obtained a dynamic model predicting the production kinetics of volatile compounds throughout the alcoholic fermentation from the initial nitrogen concentration and temperature values (called MODAPEC, for "modeling of aroma production in enological conditions"). The structure of these models and their interactions are presented in Figure 2.

\subsubsection{Transition between the two production yields}

The first step was to quantify and predict the sugar consumption corresponding to the transition between the two linear phases for the five compounds.

For the two ethyl esters, regardless of the initial temperature and YAN concentration, the transition between the two linear production phases occurred at similar levels of sugar consumption $\left(\mathrm{S}_{\text {trans }}\right)[6]$. For the two higher alcohols and the acetate ester, $S_{\text {trans }}$ was identical for the three temperatures but dependent on initial nitrogen concentration [6], systematically corresponding to the end of the growth phase (see Fig. 1b). For these three molecules, $S_{\text {trans }}$ remained constant below a threshold value 
of initial nitrogen concentration (230 mgN/L), increasing linearly thereafter (Fig. 3). Consequently, for isobutanol, isoamyl alcohol and isoamyl acetate, $S_{\text {trans }}$ (in $\mathrm{g}$ consumed sugar/L) can be expressed as follows:

$\mathrm{S}_{\text {trans }}=\left\{\begin{array}{ccc}A & \text { if } & N_{0}<230 m g N / L \\ \mathrm{~B}+\mathrm{C} \times N_{0} & \text { if } & N_{0} \geq 230 m g N / L\end{array}\right.$ Equation 1

where $\mathrm{N}_{0}$ is the initial YAN concentration $(\mathrm{mgN} / \mathrm{L})$, and $A, B$ and $C$ are constants.

\subsubsection{Production yields}

We calculated the production yields of volatile compounds from sugar, by applying two linear regressions to the nine fermentations used to build the model. Changes in these production yields were identified from the values of temperature and initial nitrogen concentration as follows:

$$
\begin{array}{ll}
\ln \mathrm{Y}_{1}=\mathrm{D}_{1}+\mathrm{D}_{2} \times \mathrm{N}_{0}+D_{3} \times T+D_{4} \times N_{0}^{2}+D_{5} \times T^{2}+D_{6} \times N_{0} \times T & \text { Equation 2 } \\
\ln \mathrm{Y}_{2}=\mathrm{D}_{7}+\mathrm{D}_{8} \times \mathrm{N}_{0}+D_{9} \times T+D_{10} \times N_{0}^{2}+D_{11} \times T^{2}+D_{12} \times N_{0} \times T & \text { Equation 3 }
\end{array}
$$

where $Y_{1}$ and $Y_{2}$ are the production yields of the volatile compound considered, from sugar, in the first and second linear phases of production, respectively, $T$ is the fermentation temperature $\left({ }^{\circ} \mathrm{C}\right), \mathrm{N}_{0}$ is the initial YAN concentration $(\mathrm{mgN} / \mathrm{L})$ and $\mathrm{D}_{1}$ to $\mathrm{D}_{12}$ are constants (model parameters).

\subsubsection{Production rates}

The rate of production of each volatile molecule (called $M$ in equation 4) was calculated from the transition threshold between the two production phases $\left(S_{\text {trans }}\right)$ and the production yield in each phase: 


$$
\frac{\mathrm{dM}}{\mathrm{dt}}=\left\{\begin{array}{lll}
Y_{1} \frac{-d S}{d t} & \text { if } & S_{0}-S(t)<S_{\text {trans }} \\
Y_{2} \frac{-d S}{d t} & \text { if } & S_{0}-S(t) \geq S_{\text {trans }}
\end{array} \text { Equation } 4\right.
$$

\subsubsection{Model parameter determination}

First, the parameters of the model $A, B$ and $C$ were determined by least squares linear regression using Equation 1, with the parameter $C$ being set to zero for the ethyl esters, as explained previously. Then, the parameters of the model $\left(D_{1} \ldots D_{12}\right)$ were determined in three steps, separately, for each of the aroma compounds considered. In the first step, $Y_{1}$ and $Y_{2}$ were calculated by linear least squares regression of the aroma compound concentration against sugar consumption (below and above $S_{\text {trans }}$ ) for each experiment. In the second step, preliminary sets of parameters $\left(D_{1} \ldots D_{6}\right.$ and $\left.D_{7} \ldots D_{12}\right)$ were estimated by linear regression, using Equations 2 and 3 , respectively. These parameter values corresponded to preliminary estimates, because the number of degrees of freedom was quite small (nine yield values used to estimate six parameters), yielding large standard errors. Finally, a full nonlinear least squares regression was performed with Equations 2, 3 and 4 , to refine the values of the parameters $D_{1} \ldots D_{12}$ simultaneously, on the basis of the measured aroma compound concentrations in all nine experiments. The preliminary values estimated in the second step were used as initial guesses for the nonlinear regression in the refinement step. The refinement step increased the accuracy of parameter value determinations and greatly decreased the standard error, due to the much larger number of degrees of freedom: several hundred concentration measurements used to estimate 12 parameters.

In the final step, parameters not significantly different from zero at a 0.05 level were iteratively removed from the model (i.e. set to exactly zero), beginning with the factor 
with the highest coefficient of variation (descending stepwise regression). The remaining parameters were recalculated and the procedure was repeated until the model contained only parameters significantly different from zero.

\subsubsection{Implementation in the MOMAF fermentation model}

Equations 1, 23 and 4 were then incorporated into the MOMAF model previously developed by Malherbe et al. [19], to obtain the final model, which we called MODAPEC. The MOMAF model predicted the kinetics of the main reaction of the fermentation process (bioconversion of sugar into ethanol and $\mathrm{CO}_{2}$ ) from the initial nitrogen concentration and the temperature profile during the winemaking fermentation. Its general equations were as follows:

$$
\begin{array}{ll}
\frac{\mathrm{dX}}{\mathrm{dt}}=\mathrm{k}_{1} \times \mathrm{X} \times\left(1-\frac{\mathrm{X}}{\mathrm{X}_{\text {max }}}\right) & \text { Equation 5 } \\
\frac{\mathrm{dS}}{\mathrm{dt}}=-\mathrm{X} \times v_{\mathrm{ST}} \times \mathrm{N}_{\mathrm{ST}} & \text { Equation 6 } \\
\frac{\mathrm{dN}}{\mathrm{dt}}=-\mathrm{X} \times v_{\mathrm{N}} & \text { Equation 7 }
\end{array}
$$

In these equations, $X$ is the size of the cell population $\left(10^{9}\right.$ cells/L), $S$ is the residual sugar concentration $(\mathrm{g} / \mathrm{L})$ and $\mathrm{N}$ is the residual YAN concentration $(\mathrm{mgN} / \mathrm{L}) ; \mathrm{k}_{1}$ is a function dependent on temperature. $X_{\max }$ is the maximum population size during stationary phase and is dependent on the initial nitrogen concentration. $v_{S T}$ is a function describing the active transport of sugar per cell; $\mathrm{N}_{\mathrm{ST}}$ is the number of sugar transporters in a cell. $v_{\mathrm{N}}$ is a function describing the active transport of nitrogen per cell. These functions were as follows:

$X_{\max }=-0.000649 \times N_{0}^{2}+0.698 \times N_{0}+7$

Equation 8

$\mathrm{k}_{1}=0.029 \times \mathrm{T}-0.376$

\section{Equation 9}


$v_{S T}=\frac{0.035 \times S}{\left.S+15+0.012 \times S \times\left[\frac{\left(S_{0}-S\right)}{0.47}\right]\right]^{1.25}}$

Equation 10

$N_{\mathrm{ST}}=0.00294 \times \mathrm{T} \times \frac{\left(\mathrm{N}_{0}-\mathrm{N}\right)}{\mathrm{X}}+0.06 \times \mathrm{T}++0.335 \times \frac{\left(\mathrm{N}_{0}-\mathrm{N}\right)}{\mathrm{X}}-1$

Equation 11

$v_{N}=\frac{N}{N+30+35 \times N \times\left[\frac{\left(S_{0}-S\right)}{0.47}\right] 1.5}$

Equation 12

\subsection{Model identification}

\subsection{1 $S_{\text {trans }}$}

For precise determination of the dependence of $S_{\text {trans }}$ on $N_{0}$, we had to obtain points uniformly distributed between 70 and $410 \mathrm{mgN} / \mathrm{L}$. We therefore used the nine fermentations presented in Mouret et al. [6] and the four fermentations performed with the SM150 and SM340 media to determine the parameters of equation 1.

As reported in section 3.1, $S_{\text {trans }}$ was constant for ethyl esters but dependent on initial nitrogen content (YAN) for the other compounds. This result is consistent with the metabolic pathways involved in the production of these compounds. Indeed, ethyl esters are produced by lipid metabolism, independently of nitrogen metabolism $[2,6]$, whereas higher alcohols and acetate esters can be produced by the metabolism of both carbon and nitrogen $[2,27]$.

For ethyl hexanoate and ethyl octanoate, $S_{\text {trans }}$ was estimated at 20 and $60 \mathrm{~g} / \mathrm{L}$, respectively (Table 1). For the other compounds, $S_{\text {trans }}$ remained constant for initial nitrogen concentrations below a threshold value (about $230 \mathrm{mgN} / \mathrm{L}$; Figure 3), subsequently increasing linearly with initial YAN concentration. This threshold concentration may be related to changes in nitrogen assimilation. Indeed, Crepin et 
al. [28] measured the rate of nitrogen assimilation and observed a marked change in this rate at a nitrogen concentration of about $260 \mathrm{mgN} / \mathrm{L}$. Parameters $B$ and $C$ in Equation 1 were estimated at $11.4 \mathrm{~g} / \mathrm{L}$ and $0.186 \mathrm{~g} / \mathrm{mg}$, respectively (Table 1).

\subsubsection{Yields}

The parameters of the model $D_{1} \ldots D_{12}$ were defined from the measurements for nine fermentations [6]. The shapes of the response surfaces were very different for $Y_{1}$ and $Y_{2}$ (Fig. $4 a$ to $6 d$ ), indicating different patterns of regulation for the metabolic pathways during the two phases of production, for all the compounds considered. This result was expected, particularly for isobutanol, isoamyl alcohol and isoamyl acetate, because the metabolic pathways involved in the synthesis of these three molecules differed considerably between the two phases of production, with both the catabolism of exogenous amino acids and central carbon metabolism during the growth phase but only central carbon metabolism during the stationary phase [6].

For isoamyl alcohol and isobutanol, the production yield of the second phase was highest for an initial nitrogen content of $230 \mathrm{mgN} / \mathrm{L}$ (Fig. $4 \mathrm{~b}$ and 5b, respectively). This observation is consistent with previous studies reporting higher alcohol synthesis to be optimal between 200 and $300 \mathrm{mgN} / \mathrm{L}[4,5,8]$. Differences in the management of keto-acid pools (precursors of higher alcohols) as a function of the type and amount of extracellular amino acids may account for these observations [6,7]. Figures $4 a, 4 b, 5 a$ and $5 b$ also highlight differences in the effects of temperature between isobutanol and isoamyl alcohol $[6,7]$, despite these compounds having an intermediate, $\alpha$-ketoisovalerate, in common. 
The differences between isoamyl alcohol and the corresponding ester (Figure 4a to $4 d)$ suggest that the synthesis of isoamyl acetate depends more strongly on the enzymatic activity of the alcohol acetyltransferases [29], Atf1p and Atf2p, than on the availability of its precursor higher alcohol. The similarities between the two ethyl esters, particularly during the second phase (Fig. 6a to 6d), are not surprising, because these two esters have very similar metabolic pathways [2].

After parameter identification, production yields were coupled to the MOMAF model to predict the kinetics of production of ethanol, isobutanol, isoamyl alcohol, isoamyl acetate, ethyl hexanoate and ethyl octanoate from the initial concentrations of sugar and nitrogen and from the initial temperature value (MODAPEC model).

\subsection{Model validation}

Figure 7 illustrates the results obtained when the MODAPEC model was used to simulate the fermentation kinetics $\left(\mathrm{dCO}_{2} / \mathrm{dt}\right)$ and dynamics of aroma synthesis (using the results obtained for the fermentation performed with $\mathrm{SM} 340$ at $26^{\circ} \mathrm{C}$ as an example). Table 2 summarizes the mean differences between the estimated and experimental values for the nine fermentations used for parameter identification and for six independent experiments.

For each experiment, the mean relative error (mean difference) between model predictions and experimental values was calculated as follows:

$\varepsilon=\frac{\frac{1}{n} \sum_{\mathrm{i}=1}^{\mathrm{n}}\left|M_{i}^{\text {experimental }}-\mathrm{M}_{i}^{\text {predicted }}\right|}{M_{n}^{\text {experimental }}-M_{1}^{\text {experimental }}} \times 100 \%$

\section{Equation 13}


where $n$ is the number of measurements available for the fermentation studied, $\mathrm{M}^{\text {experimental }}$ and $\mathrm{M}^{\text {predicted }}$ correspond to the amount of production measured experimentally and calculated with the model, respectively.

Prediction accuracy was similar for the fermentations used to build the model and for the validation experiments (Table 2). The mean difference between experimental and calculated values was systematically below $10 \%$. The MODAPEC model thus accurately predicted the production kinetics of the five volatile compounds studied.

\section{Conclusion}

The model developed here constitutes a first step towards a dynamic vision of aroma synthesis during winemaking fermentations. This dynamic model makes it possible, for the first time, to predict the kinetics of production for the main fermentative aromas - isobutanol, isoamyl alcohol, isoamyl acetate, ethyl hexanoate and ethyl octanoate - highly accurately (mean error of less than 10\%). The model also takes into account the effects of the two main factors affecting the fermentation process: the nitrogen content of the must and fermentation temperature.

The overall structure of the model would be expected to remain valid, whereas the numerical values of the coefficients are likely to change with the use of different natural musts and other yeast strains. Moreover, other parameters, such as lipid concentration or oxygen addition, may affect the production of aroma molecules, and their effects will need to be determined. However, this model opens up new perspectives for the development of innovative strategies aiming to maximize or 
minimize the synthesis of fermentative aromas, or to drive such synthesis towards specific targets, by controlling fermentation parameters.

\section{Acknowledgments}

We thank Evelyne Aguera, Magaly Angenieux, Marc Perez and Christian Picou for technical assistance. The research generating these results was funded by the European Community Seventh Framework Programme (FP7/2007e2013) under grant agreement CAFE no. KBBE-212754 (http://www.cafeproject.org). This study was also supported by the BIOFLAVOUR Cost Action FA0907.

\section{Symbols and abbreviations}
A, B, C parameters describing the dependence of $S_{\text {trans }}$ on $N_{0}$
$D_{1} \ldots D_{12} \quad$ parameters describing the dependence of $Y_{1}$ and $Y_{2}$ on $N_{0}$ and $T$
$\mathrm{k}_{1} \quad$ function involved in the modeling of biomass production
MOMAF modeling of the main reaction of alcoholic fermentation
MODAPEC modeling of aroma production in enological conditions
M total production of fermentative aroma compounds ( $\mathrm{mg} / \mathrm{L})$
$\mathrm{N} \quad$ residual nitrogen concentration $(\mathrm{mgN} / \mathrm{L})$
$\mathrm{N}_{0} \quad$ initial assimilable nitrogen concentration $(\mathrm{mgN} / \mathrm{L})$
$\mathrm{N}_{\mathrm{ST}} \quad$ function involved in the modeling of sugar consumption
S residual sugar concentration (g/L) 


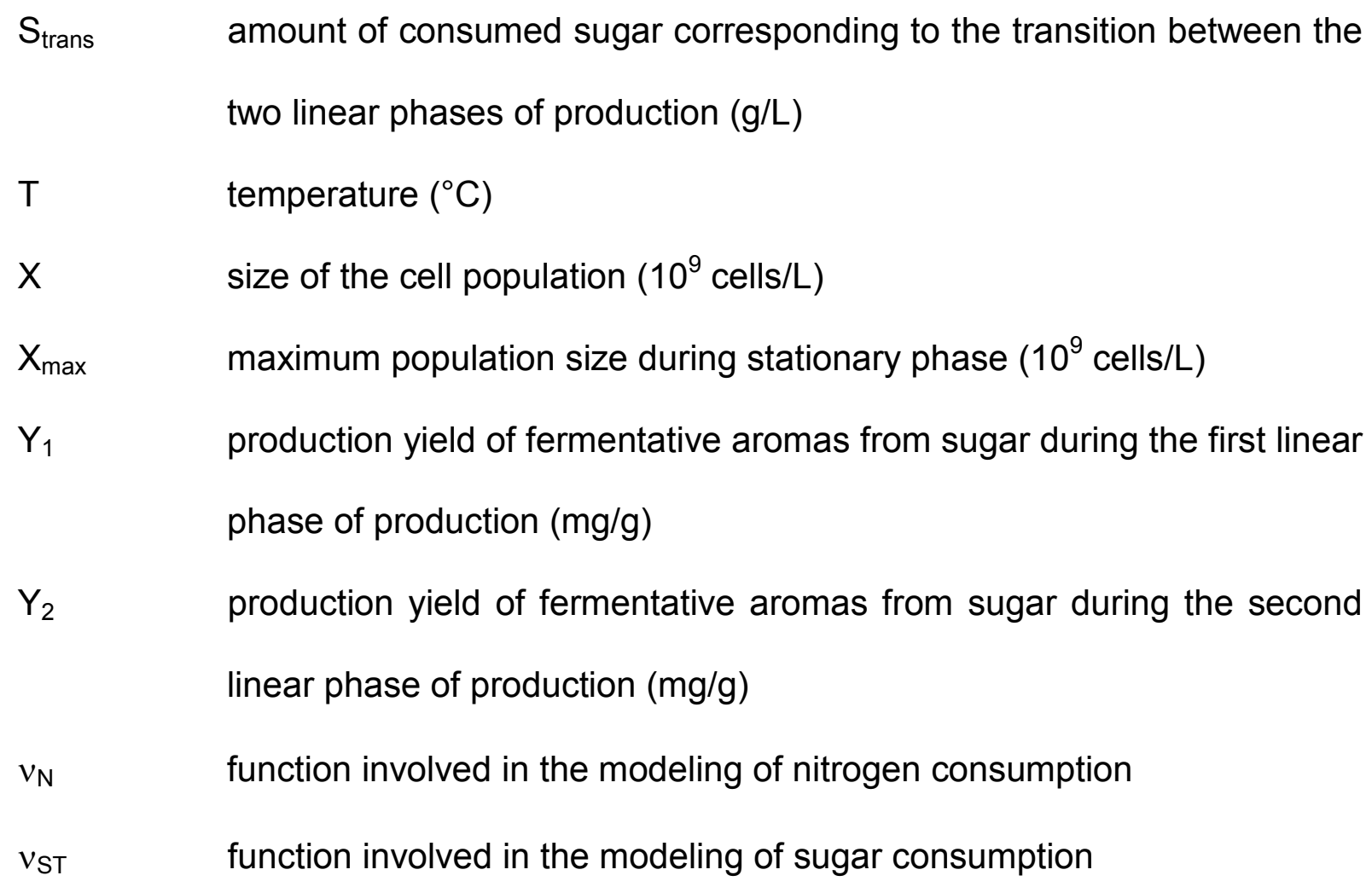

\section{References}

[1] S.-J. Lee, A.C. Noble, Characterization of odor-active compounds in Californian Chardonnay wines using GC-Olfactometry and GC-Mass spectrometry, J. Agric. Food Chem. 51 (2003) 8036-8044.

[2] J.H. Swiegers, E.J. Bartowsky, P.A. Henschke, I.S. Pretorius, Yeast and bacterial modulation of wine aroma and flavour, Aust. J. Grape Wine Res. 11 (2005) 139-173.

[3] M. Ugliano, B. Travis, I.L. Francis, P.A. Henschke, Volatile composition and sensory properties of Shiraz wines as affected by nitrogen supplementation and 
yeast species: rationalizing nitrogen modulation of wine aroma, J. Agric. Food Chem. 58 (2010) 12417-12425.

[4] F.M. Carrau, K. Medina, L. Farina, E. Boido, P.A. Henschke, E. Dellacassa, Production of fermentation aroma compounds by Saccharomyces cerevisiae wine yeasts: effects of yeast assimilable nitrogen on two model strains, FEMS Yeast Res. 8 (2008) 1196-1207.

[5] E. Jiménez-Martí, A. Aranda, A. Mendes-Ferreira, A. Mendes-Faia, M. Ií del Olmo, The nature of the nitrogen source added to nitrogen depleted vinifications conducted by a Saccharomyces cerevisiae strain in synthetic must affects gene expression and the levels of several volatile compounds, Antonie Van Leeuwenhoek. 92 (2007) 61-75.

[6] J.-R. Mouret, C. Camarasa, M. Angenieux, E. Aguera, M. Perez, V. Farines, J.M. Sablayrolles, Kinetic analysis and gas-liquid balances of the production of fermentative aromas during winemaking fermentations: Effect of assimilable nitrogen and temperature, Food Res. Int. 62 (2014) 1-10.

[7] S. Rollero, A. Bloem, C. Camarasa, I. Sanchez, A. Ortiz-Julien, J.-M. Sablayrolles, J.-R. Mouret, Combined effects of nutrients and temperature on the production of fermentative aromas by Saccharomyces cerevisiae during wine fermentation, Appl. Microbiol. Biotechnol. 99 (2015) 2291-2304.

[8] M. Vilanova, T.E. Siebert, C. Varela, I.S. Pretorius, P.A. Henschke, Effect of ammonium nitrogen supplementation of grape juice on wine volatiles and nonvolatiles composition of the aromatic grape variety Albariño, Food Chem. 133 (2012) 124-131.

[9] T. Garde-Cerdán, C. Ancín-Azpilicueta, Effect of the addition of different quantities of amino acids to nitrogen-deficient must on the formation of esters, 
alcohols, and acids during wine alcoholic fermentation, LWT - Food Sci. Technol. 41 (2008) 501-510.

[10] P. Hernandez-Orte, M. Bely, J. Cacho, V. Ferreira, Impact of ammonium additions on volatile acidity, ethanol, and aromatic compound production by different Saccharomyces cerevisiae strains during fermentation in controlled synthetic media, Aust. J. Grape Wine Res. 12 (2006) 150-160.

[11] D. Torrea, C. Varela, M. Ugliano, C. Ancin-Azpilicueta, I. Leigh Francis, P.A. Henschke, Comparison of inorganic and organic nitrogen supplementation of grape juice - Effect on volatile composition and aroma profile of a Chardonnay wine fermented with Saccharomyces cerevisiae yeast, Food Chem. 127 (2011) 1072-1083.

[12] G. Beltran, M. Novo, J.M. Guillamón, A. Mas, N. Rozès, Effect of fermentation temperature and culture media on the yeast lipid composition and wine volatile compounds, Int. J. Food Microbiol. 121 (2008) 169-177.

[13] A. Gamero, J. Tronchoni, A. Querol, C. Belloch, Production of aroma compounds by cryotolerant Saccharomyces species and hybrids at low and moderate fermentation temperatures, J. Appl. Microbiol. 114 (2013) 1405-1414.

[14] A.M. Molina, J.H. Swiegers, C. Varela, I.S. Pretorius, E. Agosin, Influence of wine fermentation temperature on the synthesis of yeast-derived volatile aroma compounds, Appl. Microbiol. Biotechnol. 77 (2007) 675-687.

[15] M.C. Coleman, R. Fish, D.E. Block, Temperature-dependent kinetic model for nitrogen-limited wine fermentations, Appl. Environ. Microbiol. 73 (2007) 58755884 .

[16] A.C. Cramer, S. Vlassides, D.E. Block, Kinetic model for nitrogen-limited wine fermentations, Biotechnol. Bioeng. 77 (2002) 49-60. 
[17] R. David, D. Dochain, J.-R. Mouret, A.V. Wouwer, J.-M. Sablayrolles, Nitrogenbackboned modeling of wine-making in standard and nitrogen-added fermentations, Bioprocess Biosyst. Eng. 37 (2013) 5-16.

[18] G. Insa, J. Sablayrolles, V. Douzal, Alcoholic fermentation under enological conditions - use of a combination of data-analysis and neural networks to predict sluggish and stuck fermentations, Bioprocess Eng. 13 (1995) 171-176.

[19] S. Malherbe, V. Fromion, N. Hilgert, J.-M. Sablayrolles, Modeling the effects of assimilable nitrogen and temperature on fermentation kinetics in enological conditions, Biotechnol. Bioeng. 86 (2004) 261-272.

[20] F. Pizarro, C. Varela, C. Martabit, C. Bruno, J.R. Pérez-Correa, E. Agosin, Coupling kinetic expressions and metabolic networks for predicting wine fermentations, Biotechnol. Bioeng. 98 (2007) 986-998.

[21] J. Sainz, F. Pizarro, J.R. Pérez-Correa, E. Agosin, Modeling of yeast metabolism and process dynamics in batch fermentation, Biotechnol. Bioeng. 81 (2003) 818-828.

[22] F.A. Vargas, F. Pizarro, J.R. Pérez-Correa, E. Agosin, Expanding a dynamic flux balance model of yeast fermentation to genome-scale, BMC Syst. Biol. 5 (2011) 75.

[23] J.R. Mouret, M. Perez, M. Angenieux, P. Nicolle, V. Farines, J.M. Sablayrolles, Online-based kinetic analysis of higher alcohol and ester synthesis during winemaking fermentations, Food Bioprocess Technol. 7 (2014) 1235-1245.

[24] M. Bely, J. Sablayrolles, P. Barre, Automatic detection of assimilable nitrogen deficiencies during alcoholic fermentation in enological conditions, J. Ferment. Bioeng. 70 (1990) 246-252. 
[25] S. Morakul, J.-R. Mouret, P. Nicolle, I.C. Trelea, J.-M. Sablayrolles, V. Athes, Modelling of the gas-liquid partitioning of aroma compounds during wine alcoholic fermentation and prediction of aroma losses, Process Biochem. 46 (2011) 1125-1131.

[26] S. Morakul, J.-R. Mouret, P. Nicolle, E. Aguera, J.-M. Sablayrolles, V. Athes, A dynamic analysis of higher alcohol and ester release during winemaking fermentations, Food Bioprocess Technol. 6 (2013) 818-827.

[27] C. van Der Sluis, Y.S.P. Rahardjo, B.A. Smit, P.J. Kroon, S. Hartmans, E.G. Ter Schure, et al., Concomitant extracellular accumulation of alpha-keto acids and higher alcohols by Zygosaccharomyces rouxii, J. Biosci. Bioeng. 93 (2002) 117124.

[28] L. Crépin, I. Sanchez, T. Nidelet, S. Dequin, C. Camarasa, Efficient ammonium uptake and mobilization of vacuolar arginine by Saccharomyces cerevisiae wine strains during wine fermentation, Microb. Cell Factories. 13 (2014) 109.

[29] M. Lilly, M.G. Lambrechts, I.S. Pretorius, Effect of increased yeast alcohol acetyltransferase activity on flavor profiles of wine and distillates, Appl. Environ. Microbiol. 66 (2000) 744-753. 


\section{Figures}

Fig 1
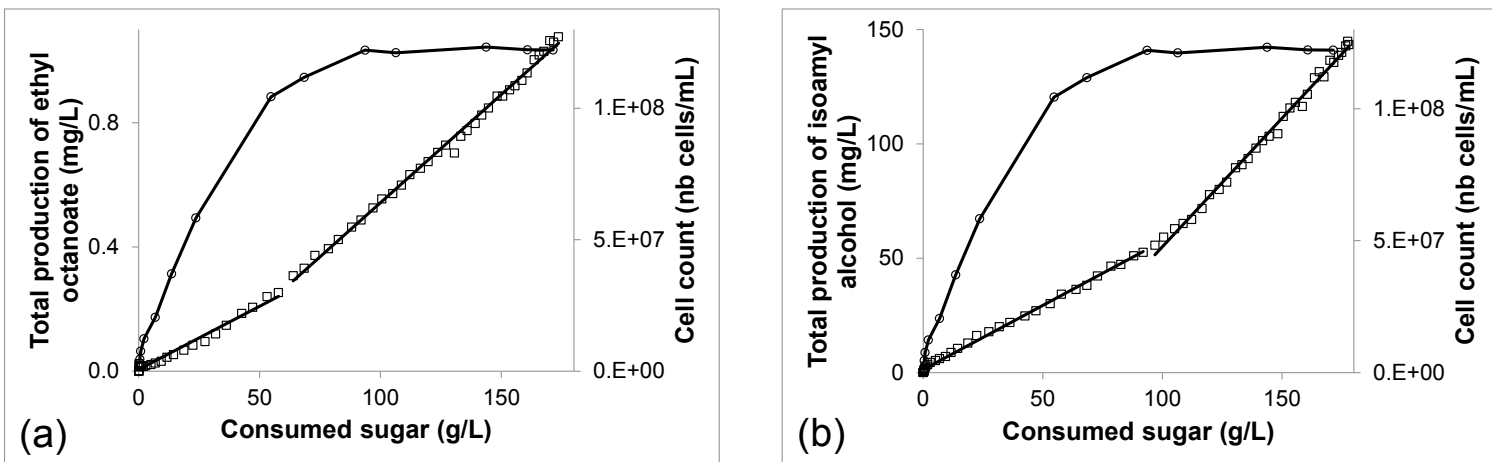

Fig. 1. (a) Changes in the total production of ethyl octanoate $(\square)$ and cell count $(O)$ as a function of sugar consumption. For the two successive linear phases, the regression coefficients were 0.979 and 0.995 , respectively. (b) Changes in the total production of isoamyl alcohol $(\square)$ and cell count $(O)$ as a function of sugar consumption. For the two successive linear phases, the regression coefficients were 0.997 and 0.994 , respectively. For the two graphs, the initial nitrogen concentration was $410 \mathrm{mgN} / \mathrm{L}$ and the fermentation temperature was $24^{\circ} \mathrm{C}$. 


\section{Fig 2}

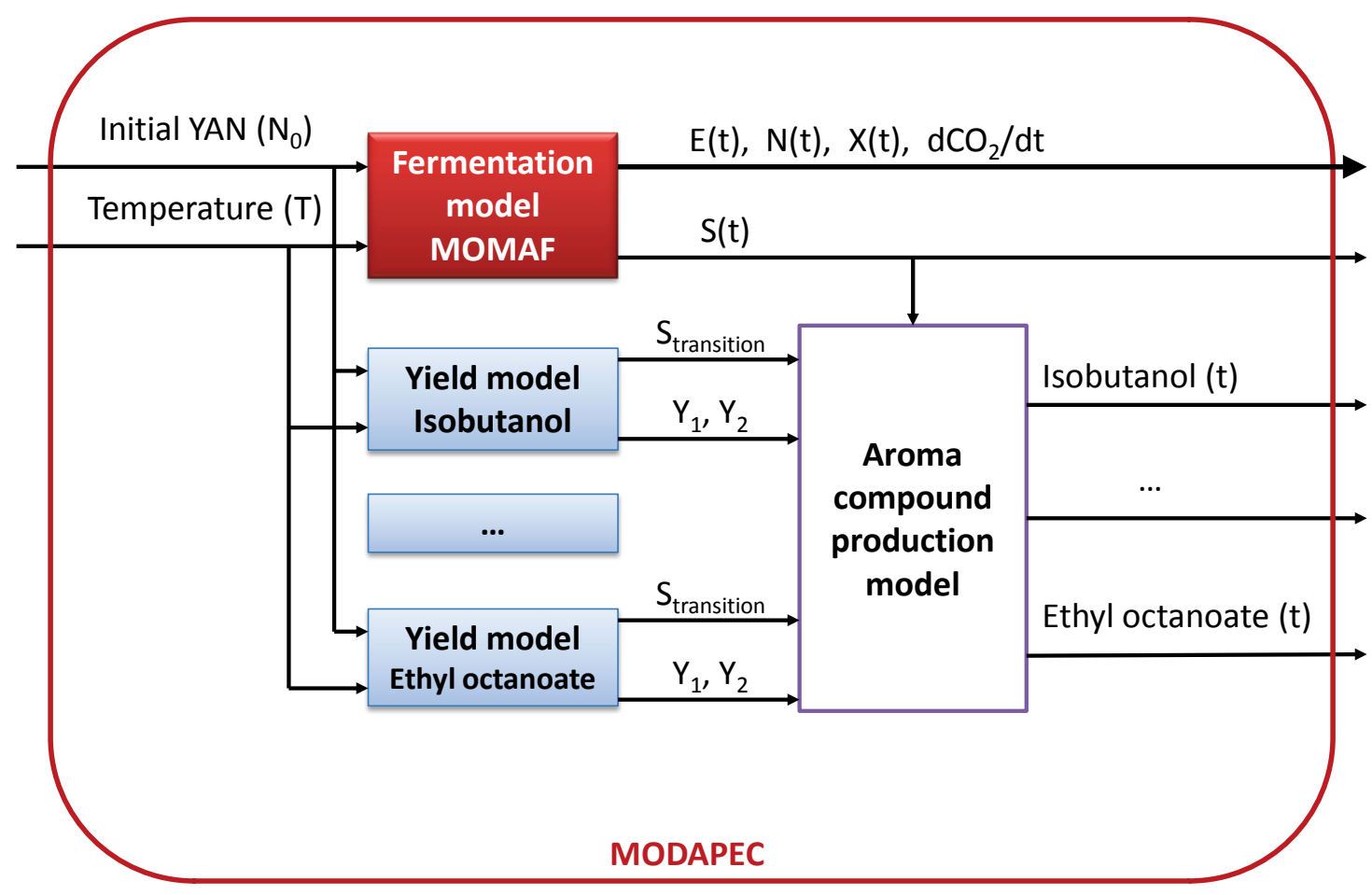

Fig. 2. Structure of the MODAPEC model.

Parameters of the MOMAF model and production yields of aroma compounds from sugar $\left(Y_{1}, Y_{2}\right)$ are calculated from initial nitrogen content $\left(N_{0}\right)$ and temperature $(T)$. At each time point during the fermentation, the production of the volatile compounds was calculated by multiplying the amount of sugar consumed, $S(t)$, by the corresponding production yield. 


\section{Fig 3}

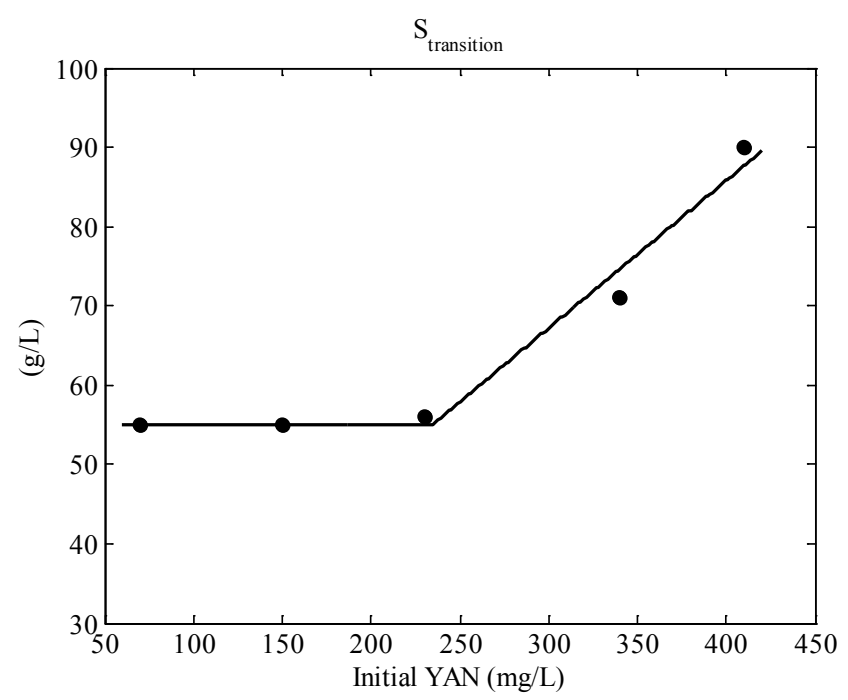

Fig. 3. Changes in the amount of sugar consumed ( $\left.S_{\text {trans }}\right)$ corresponding to the transition between the two phases of linear production of isobutanol, isoamyl alcohol and isoamyl acetate as a function of initial yeast assimilable nitrogen concentration. For the linear phase starting at $230 \mathrm{mgN} / \mathrm{L}$, the regression coefficient was 0.996 . 
Fig 4
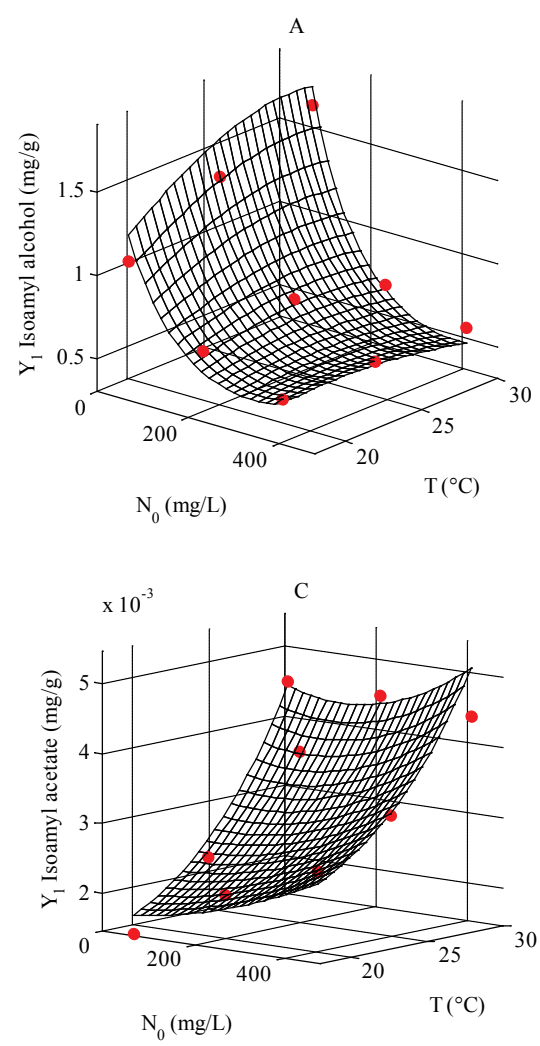
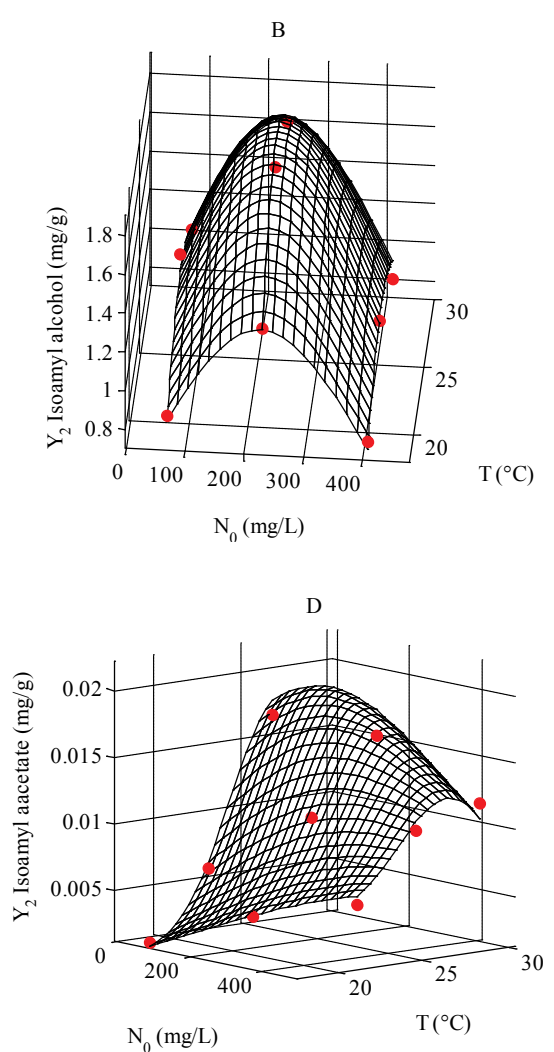

Fig. 4. Response surfaces for production yields during the first $\left(Y_{1}\right)$ and second $\left(Y_{2}\right)$ linear phases of production. $4 \mathrm{a}$ and $4 \mathrm{~b}$ : isoamyl alcohol. $4 \mathrm{c}$ and $4 \mathrm{~d}$ : isoamyl acetate. 


\section{Fig 5}
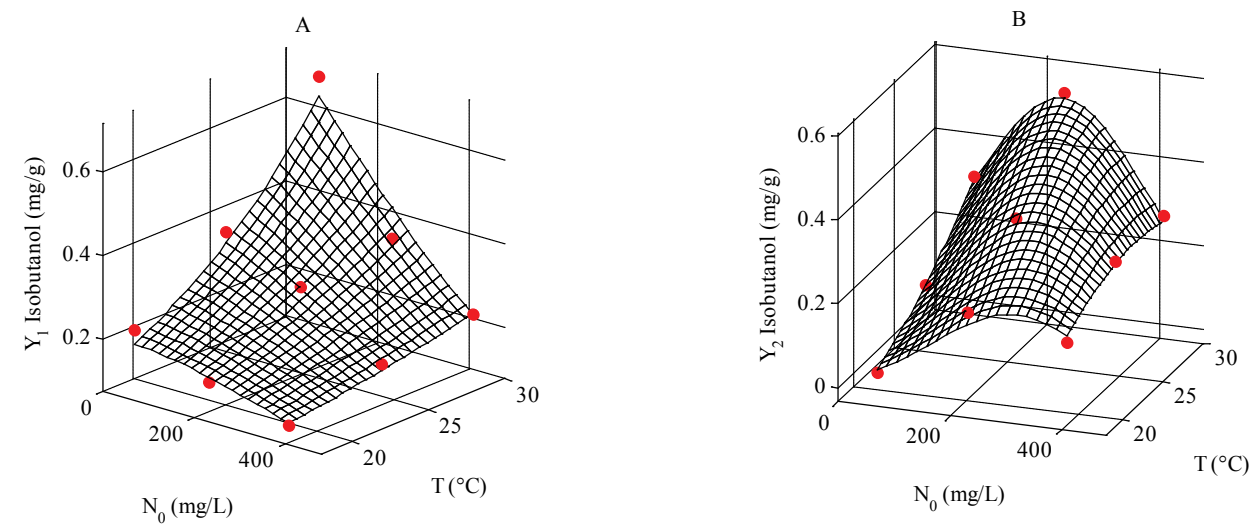

Fig. 5. Response surfaces for production yields of isobutanol during the first $\left(\mathrm{Y}_{1}\right)$ and second $\left(\mathbf{Y}_{2}\right)$ linear phases of production. 
Fig 6
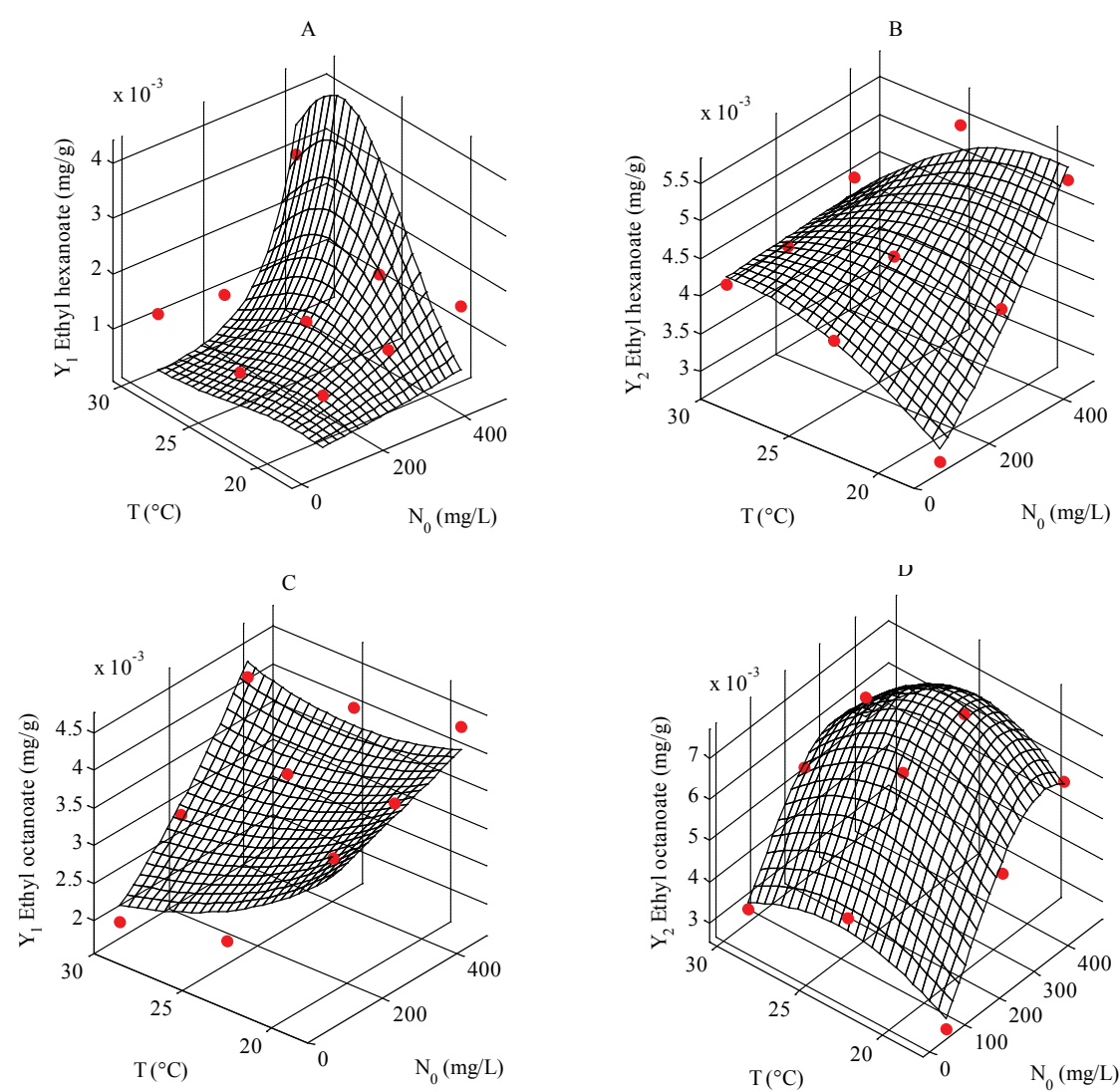

Fig. 6. Response surfaces of production yields during the first $\left(Y_{1}\right)$ and second $\left(Y_{2}\right)$ linear phases of production. $6 a$ and $6 \mathrm{~b}$ : ethyl hexanoate. $6 \mathrm{c}$ and $6 \mathrm{~d}$ : ethyl octanoate. 


\section{Fig 7}
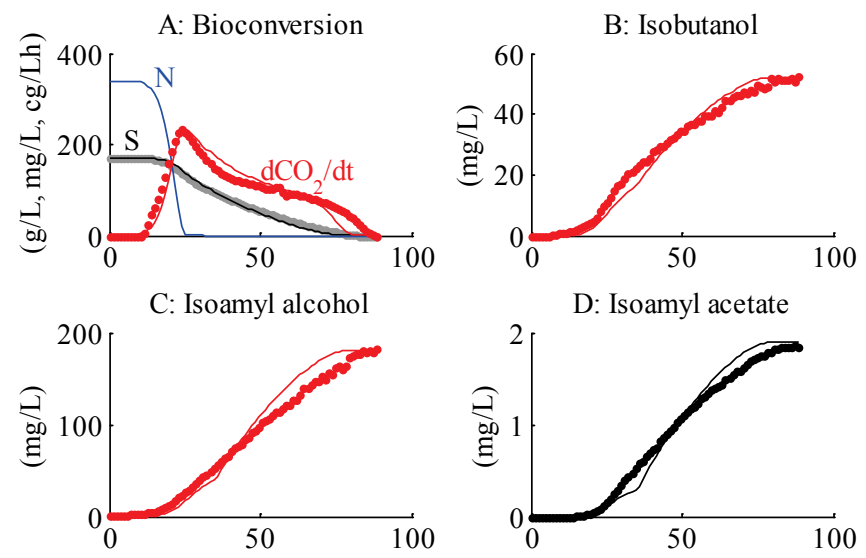

D: Isoamyl acetate
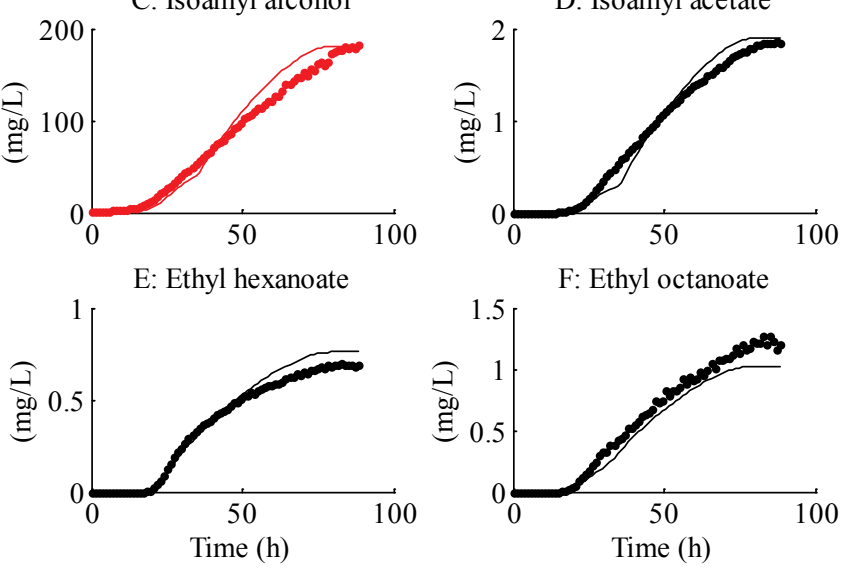

Fig. 7. Changes in the rate of $\mathrm{CO}_{2}$ production (a), total production of isobutanol (b), isoamyl alcohol (c), isoamyl acetate (d), ethyl hexanoate (e) and ethyl octanoate (f) as a function of time. On each graph, the experimental data are represented by dots, whereas the continuous line corresponds to the values calculated by the model. The results presented are those for $\mathrm{SM} 340$ at $26^{\circ} \mathrm{C}$, conditions used for model validation only. 
Table 1

\begin{tabular}{|c|c|c|c|c|c|}
\hline & Isobutanol & $\begin{array}{c}\text { Isoamyl } \\
\text { alcohol }\end{array}$ & $\begin{array}{c}\text { Isoamyl } \\
\text { aceate }\end{array}$ & $\begin{array}{c}\text { Ethyl } \\
\text { hexanoate }\end{array}$ & $\begin{array}{c}\text { Ethyl } \\
\text { octanoate }\end{array}$ \\
\hline A & 55 & 55 & 55 & 20 & 60 \\
\hline B & 11.4 & 11.4 & 11.4 & 20 & 60 \\
\hline C & 0.186 & 0.186 & 0.186 & - & - \\
\hline
\end{tabular}

Table 2

\begin{tabular}{|c|c|c|c|c|c|}
\hline & Isobutanol & $\begin{array}{l}\text { Isoamyl } \\
\text { alcohol }\end{array}$ & $\begin{array}{l}\text { Isoamyl } \\
\text { acetate }\end{array}$ & $\begin{array}{c}\text { Ethyl } \\
\text { hexanoate }\end{array}$ & $\begin{array}{c}\text { Ethyl } \\
\text { octanoate }\end{array}$ \\
\hline \multicolumn{6}{|l|}{ Identification } \\
\hline $\mathrm{SM} 70-18^{\circ} \mathrm{C}$ & $6 \%$ & $2 \%$ & $6 \%$ & $2 \%$ & $5 \%$ \\
\hline $\mathrm{SM} 70-24^{\circ} \mathrm{C}$ & $4 \%$ & $3 \%$ & $3 \%$ & $5 \%$ & $5 \%$ \\
\hline $\mathrm{SM} 70-30^{\circ} \mathrm{C}$ & $7 \%$ & $7 \%$ & $13 \%$ & $3 \%$ & $8 \%$ \\
\hline $\mathrm{SM} 230-18^{\circ} \mathrm{C}$ & $5 \%$ & $6 \%$ & $7 \%$ & $6 \%$ & $4 \%$ \\
\hline SM230- $24^{\circ} \mathrm{C}$ & $5 \%$ & $7 \%$ & $10 \%$ & $3 \%$ & $4 \%$ \\
\hline $\mathrm{SM} 230-30^{\circ} \mathrm{C}$ & $2 \%$ & $6 \%$ & $7 \%$ & $1 \%$ & $2 \%$ \\
\hline $\mathrm{SM} 410-18^{\circ} \mathrm{C}$ & $11 \%$ & $4 \%$ & $11 \%$ & $4 \%$ & $4 \%$ \\
\hline $\mathrm{SM} 410-24^{\circ} \mathrm{C}$ & $3 \%$ & $3 \%$ & $3 \%$ & $5 \%$ & $4 \%$ \\
\hline $\mathrm{SM} 410-30^{\circ} \mathrm{C}$ & $3 \%$ & $3 \%$ & $5 \%$ & $3 \%$ & $3 \%$ \\
\hline Average & $5 \%$ & $5 \%$ & $7 \%$ & $4 \%$ & $4 \%$ \\
\hline \multicolumn{6}{|l|}{ Validation } \\
\hline SM230-24 ${ }^{\circ} \mathrm{C}$ _bis & $8 \%$ & $8 \%$ & $4 \%$ & $7 \%$ & $7 \%$ \\
\hline SM230-24 ${ }^{\circ}$ C_third & $8 \%$ & $4 \%$ & $8 \%$ & $6 \%$ & $8 \%$ \\
\hline $\mathrm{SM} 150-21^{\circ} \mathrm{C}$ & $9 \%$ & $6 \%$ & $7 \%$ & $6 \%$ & $7 \%$ \\
\hline SM150-26 ${ }^{\circ} \mathrm{C}$ & $5 \%$ & $6 \%$ & $8 \%$ & $7 \%$ & $7 \%$ \\
\hline $\mathrm{SM} 340-21^{\circ} \mathrm{C}$ & $8 \%$ & $6 \%$ & $4 \%$ & $6 \%$ & $7 \%$ \\
\hline $\mathrm{SM} 340-26^{\circ} \mathrm{C}$ & $5 \%$ & $7 \%$ & $5 \%$ & $5 \%$ & $7 \%$ \\
\hline Average & $7 \%$ & $6 \%$ & $6 \%$ & $6 \%$ & $7 \%$ \\
\hline
\end{tabular}

